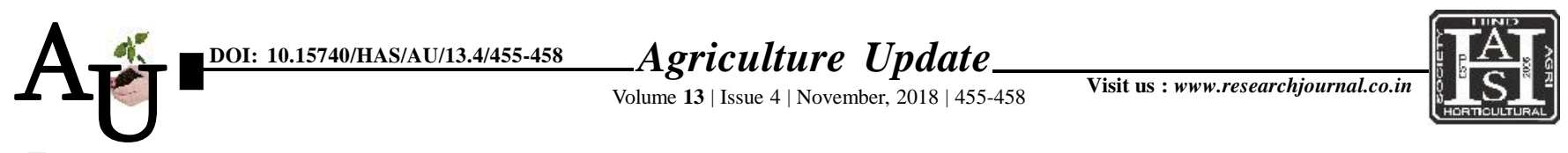

ISSN-0973-1520

\title{
Research Автіcle: Farmers knowledge of IPM practices in cabbage
}

\section{Girish and S.V. Halakatti}

Article Chronicle: Received :

08.08.2018;

Revised :

02.10.2018;

Accepted :

19.10.2018

KEY Words:

Integrated pest management (IPM), Neem seed kernal extract (NSKE)

Author for correspondence :

\section{S.V. Halakatti}

Department of

Agricultural Extension

Education, University of

Agricultural Sciences,

Dharwad (Karnataka)

India

Email: halakattisv@

usad.in

See end of the article for authors' affiliations
SUMMARY : The study was an "expost-facto" research carried out in Belagavi and Haveri districts of Karnataka State during the year 2017-18. Three taluks were selected in each district based on the highest area. The total sample size was 150 . The results revealed that cent per cent of farmers have correct knowledge about summer ploughing. Most $(92.66 \%)$ of the farmers were having high knowledge on regular destruction of damaged plants and 80.00 per cent of farmers have knowledge on spraying of NSKE. Almost all (98.66 \%) the farmers having knowledge about using chemical for control of diamond black moth. The overall knowledge of farmers about IPM practices in cabbage showed that 51.33 per cent of the respondents belonged to medium level of knowledge about IPM practices in cabbage followed by low $(28.66 \%)$ and high $(20.00 \%)$. The probable reasons might be that less education level, lack of training, non-utilization of mass media and less extension contact. So there is a great scope to design more number of skill trainings, demonstration and exposure visits by the development departments.

How to cite this article : Girish, D. and Halakatti, S.V. (2018). Farmers knowledge of IPM practices in cabbage. Agric. Update, 13(4): 455-458; DOI : 10.15740/HAS/AU/13.4/455-458. Copyright@2018: Hind Agri-Horticultural Society. 